Acta Poetica $33 \cdot 2$

JULIO-DICIEMBRE

$2012(31-45)$

\title{
Hermann Oldenberg y el imperativo histórico: escribiendo una biografía del Buddha Gautama desde la Alemania decimonónica
}

\author{
Roberto Eduardo García Fernández
}

En la segunda mitad del siglo xIX el budismo era ya una religión bien conocida entre los círculos académicos y literarios en Europa. Sin embargo, la multiplicidad de textos y versiones doctrinales de las diferentes escuelas budistas planteaba un dilema a los estudiosos pioneros en el campo: ¿cuál era la verdadera historia y enseñanza del Buddha? Aunque se produjeron numerosos estudios y versiones biográficas sobre el Buddha, la redactada por el orientalista alemán Hermann Oldenberg resalta por su reconstrucción historicista y su pretensión de haber utilizado las fuentes originales.

En este artículo se analiza la forma en la que la obra de Oldenberg representó un esfuerzo por reconstruir una hagiografía a través de la óptica de una sociedad moderna y racionalista que exigía coherencia con respecto a los hechos religiosos, imponiendo una perspectiva totalizadora a un material heterogéneo que en sí mismo es fragmentario, y contribuyendo de esta manera a la "construcción" de la vida del Buddha Gautama como un todo coherente.

Palabras ClaVe: budismo, biografía sagrada, historicismo, mito, orientalismo.

In the second half of the nineteenth century Buddhism was well known as a religion among academic and literary circles in Europe. However, the variety of doctrinal versions and texts from different Buddhist schools posed a dilemma for the pioneering scholars in the field: which one was the real history and teaching of the Buddha? Although there were numerous studies and biographical versions of the life of Buddha, the one written by German Orientalist Hermann Oldenberg is noted for its historicist reconstruction and its claim to have used the original source. 
This article discusses how Oldenberg's work represented an effort to reconstruct a hagiography through the lens of a modern rational society that demanded consistency with respect to religious events, imposing a holistic perspective to a heterogeneous material which in itself is fragmented, and thus contributing to the "construction" of the life of Gautama Buddha as a coherent whole.

KeYwords: Buddhism, Sacred Biography, Historicism, Myth, Orientalism.

Fecha de recepción: 10 de diciembre de 2011

Fecha de aceptación: 17 de mayo de 2012 
Roberto Eduardo García Fernández

El Colegio de México

\section{Hermann Oldenberg y el imperativo histórico: escribiendo una biografía del Buddha Gautama desde la Alemania decimonónica}

En 1881, con tan solo 26 años de edad, el orientalista alemán Hermann Oldenberg (1854-1920) publicó una de las obras decimonónicas más influyentes dentro del estudio del budismo, Buddha. Sein Leben, seine Lehre, seine Gemeinde [Buddha. Su vida, su doctrina, su comunidad]. ${ }^{1}$ Esta obra monumental es, a la vez, un ejercicio literario y una exploración sociológica y filosófica de diversos aspectos del budismo que en su época eran conocidos únicamente por un selecto grupo de especialistas. Su éxito fue tal que en vida del autor se realizaron cinco ediciones revisadas en alemán, y se tradujo varias veces al inglés, francés y ruso (Welbon, "Hermann Oldenberg", 194). Sin duda, la importancia del Buddha de Oldenberg radica, en parte, en el hecho de que brindó un análisis erudito y crítico del budismo a un público no especializado, formando parte, junto con el poema The Light of Asia de Edwin Arnold de 1879 , del conjunto de obras que mayor influencia tuvieron en el proceso de formación de un imaginario europeo popular en torno a esa religión.

En buena medida, el Buddha de Oldenberg representó una innovación dentro de los estudios budistas en Europa debido a que una parte considerable de su contenido está construido a la manera de una biografía histórica del Buddha, una labor literaria sin precedentes dentro de la

\footnotetext{
${ }^{1}$ A partir de este momento aparecerá como Buddha.
} 
empresa orientalista europea, y completamente ajena a las tradiciones budistas indias. De hecho, nos dice Shaner, desde que se publicó, hasta épocas recientes, "la obra de Oldenberg se consideraba como el estándar contra el cual se evaluaban todas las otras biografías" del Buddha ("Biographies of the Buddha", 314). Tomando en consideración la importancia que el Buddha ha tenido en la historia de los estudios budistas $y$ en el entendimiento general del budismo en occidente, es pertinente preguntarnos: ¿cuál era la necesidad de reconocer la validez histórica de un personaje religioso como el Buddha en la Alemania decimonónica, y qué función tenía la composición de una biografía histórica de este personaje para el estudio y entendimiento del budismo en Europa?

\section{La biografía sagrada en el sur de Asia ${ }^{2}$}

Las tradiciones budistas del sur de Asia no produjeron biografías del Buddha en el sentido moderno de la palabra. Como en el caso de otras religiones, en el momento de representar la vida y hazañas de su fundador, los escritores budistas no establecieron distinción alguna entre los hechos históricamente comprobables y aquellos situados en el ámbito de lo maravilloso, a los que muchos estudiosos modernos considerarían como sucesos míticos. Para los antiguos budistas - así como para muchos actuales - esta distinción es no solamente innecesaria sino también absurda. No se puede despojar la vida del Buddha de sus elementos prodigiosos, pues en muchas ocasiones estos son la confirmación de su carácter extraordinario y sobrehumano. Para ellos el Buddha no era un ser humano común y corriente, y justamente muchos episodios de su vida así lo atestiguan. Como afirma Ray:

Las nociones occidentales y modernas de que existe una individualidad desmitificada aparte del símbolo, el culto y la leyenda, no tienen relevan-

${ }^{2}$ Usaré aquí el concepto de biografía sagrada en el sentido que Schober y otros (Sacred Biography in the Buddhist Traditions of South and Southeast Asia) le han dado al aplicarlo a los relatos de la vida del Buddha y otros personajes budistas, para distinguirlos por un lado de la tradición hagiográfica cristiana, y por otro de la biografía histórica. 
cia para el caso del budismo temprano. Gautama, en su propio tiempo y en épocas posteriores, pudo ser el Buddha, precisamente porque se entendía que personificaba, de una manera sin precedentes, lo cósmico y lo trascendente. Lejos de ser incidentales en cuanto a quien era, el mito y el culto definían su persona esencial, tanto para sus seguidores tempranos como para los budistas posteriores ("Buddha Śākyamuni”, 62).

En parte debido a esta postura, es imposible encontrar obras budistas antiguas que pretendan abarcar de manera cronológica todas las etapas de la vida del Buddha, desde su nacimiento hasta su muerte. Aquellas composiciones que relatan su vida se concentran solamente en un episodio en particular o en un periodo específico de su vida. El Buddhacarita, un texto sánscrito del poeta Aśvaghoșa del siglo II, es quizá la obra más ambiciosa en este sentido, y únicamente narra desde su nacimiento hasta poco tiempo después de su despertar a los 35 años. Si consideramos que las distintas tradiciones budistas aceptan que el Buddha vivió hasta los 80 años, nos daremos cuenta de que una obra del tipo del Buddhacarita no cumple los estándares de la biografía moderna que exige el recuento de la totalidad de la vida de un individuo. ${ }^{3}$

Y sin embargo, el elemento biográfico está presente en la mayor parte de composiciones budistas, ya sea como tema central, ya sea como marco narrativo. Como señala Woodward, el imperativo biográfico en el budismo es tal, que incluso las obras filosóficas y abstractas integran episodios biográficos como marco de referencia para indicar bajo qué circunstancias se explicó tal o cual doctrina ("The Biographical Imperative", 46).

Se entenderá entonces que los budistas de tiempos antiguos concebían la biografía sagrada del Buddha de una manera muy distinta de

${ }^{3}$ Además del Buddhacarita, otras composiciones de carácter biográfico relativas al Buddha que vale la pena mencionar aquí son, en lengua pāli, el Jātakațthakathā, un comentario no canónico del siglo v sobre las vidas pasadas del Buddha; el Nidānakathā, la introducción a ese comentario; el Ariyapariyesana sutta, una narración que cubre desde la renuncia del Buddha hasta la obtención del despertar y el primer sermón; el Mahāparinibbāna sutta, un recuento de los últimos días y de la muerte del Buddha. En lengua sánscrita destacan el Lalitavistara, un poema que narra las hazañas maravillosas del Buddha; y el Catusparișat-sutra, un relato del surgimiento y los primeros tiempos de la orden budista. Esta lista de ninguna manera agota las referencias a textos biográficos sobre el Buddha. 
como lo haría un europeo del siglo XIX. Para aquellos no importaba tanto enfatizar la sucesión cronológica de todos los sucesos registrables, como remarcar episodios específicos particularmente significativos que por un lado ejemplificaran de manera concreta los alcances prácticos de la doctrina, y por otro fueran testimonios indiscutibles del carácter extraordinario y particular del Buddha.

Ahora bien, puesto que los episodios o elementos prodigiosos dentro de las biografías sagradas han sido y son altamente significativos para los creyentes budistas - en ocasiones incluso más que aquellos elementos que en última instancia pudiéramos considerar como históricosante la pregunta ¿quién fue el Buddha?, quizá deberíamos formularla de la manera siguiente: "¿Cómo entendían o interpretaban al Buddha las distintas tradiciones budistas?" (Cho, "The Rationalist Tendency", 427).

Como veremos, en su Buddha, Oldenberg estaba muy lejos de abordar la biografía del Buddha desde una perspectiva abierta a las interpretaciones propias de las diversas tradiciones budistas. En un sentido su aproximación era más estrecha, pero al mismo tiempo apuntaba a las necesidades propias de una práctica académica incipiente que exigía un enfoque particularmente centrado en el carácter histórico de la religión.

\section{Hermann Oldenberg y la biografía histórica del Buddha}

Así inicia el Buddha de Oldenberg: "La historia de la fe budista comienza con un grupo de monjes mendicantes que se reunieron alrededor de la persona de Gotama, el Buddha, en la cuenca del Ganges, alrededor de la mitad del primer milenio antes del inicio de la era cristiana" (1). Sin mayor preámbulo, sin una discusión sobre las fuentes, e incluso ignorando por completo discusiones previas sobre la historicidad del Buddha, Oldenberg introduce de forma directa lo que para él es un hecho indiscutible: el carácter histórico de la vida del Buddha.

El plan de su obra está dividido en tres partes principales: la vida del Buddha, su enseñanza y su comunidad de monjes. Es en la primera sección que Oldenberg desarrolla una versión casi desconocida hasta entonces de la vida del Buddha: un recuento biográfico basado en una discusión de la veracidad histórica de algunos elementos de las bio- 
grafías sagradas. Como hemos visto, en la India antigua no existía esta necesidad de separar los elementos históricos de los no históricos en lo que respecta a la biografía del Buddha. Sin embargo, para Oldenberg esto era un imperativo. Él pertenecía a una generación de orientalistas eruditos para quienes el budismo debía entenderse no únicamente en su dimensión religiosa, sino también histórica y social. En este sentido, afirma que es necesario "rastrear la tradición hasta su forma más antigua, antes de formarse una opinión al respecto" (75), con lo cual deja claro que su intención es trabajar con los estratos más antiguos de la tradición budista, y por lo tanto, para él, los más genuinos. Al respecto, Schober señala que un grupo de orientalistas, Oldenberg entre ellos, "buscaron reconstruir un recuento históricamente preciso de la vida del Buddha fundamentándose en evidencia textual. Consideraban los elementos míticos de los textos biográficos como irracionales y apartados del mensaje 'original' del budismo "puro" " ("Trajectories", 3 ).

Desde su perspectiva, no era relevante entender la manera en que los mismos budistas habían interpretado la vida del Buddha. Le interesaba más hacer una reconstrucción científica que arrojara datos precisos sobre los hechos "originales". Había que hallar las huellas específicas de la verdad histórica dentro del "montón de fábulas que la tradición ofrece" (Oldenberg,79).

En su búsqueda del budismo "puro" y "original", Oldenberg se dirige hacia las escrituras en lengua $p \bar{a} l i$, las cuales conforman uno de los cánones budistas más antiguos. En este aspecto se distancia completamente de otros orientalistas de tiempos anteriores quienes habían echado mano principalmente de las fuentes sánscritas. La primera gran obra de los estudios budistas en Europa, la Introduction à l'histoire du Bouddhisme indien (1844) [Introducción a la historia del budismo indio] del francés Eugène Burnouf (1801-1852), estaba escrita, casi enteramente, a partir de su estudio de manuscritos sánscritos del norte de India. ${ }^{4}$ Sin embargo, a pesar de su importancia para las tradiciones bu-

${ }^{4}$ La llegada de estos manuscritos a varias universidades europeas fue obra de Brian Houghton Hodgson, un inglés que trabajaba para la East India Company en Nepal. Durante su labor civil en Katmandú, Hodgson se encargó de recopilar cientos de manuscritos budistas en lengua sánscrita, con lo que hizo accesible el estudio directo de los textos. 
distas, los textos sánscritos rápidamente perdieron validez ante los ojos de la academia europea como fuentes confiables de información histórica, siendo que estaban asociados al budismo Mahāyāna, un conjunto de tradiciones que en aquella época se consideraban como una distorsión del budismo "original".

Los textos pāli, pertenecientes al canon de la escuela budista Theravāda con presencia importantísima en algunos países del sureste de Asia, comenzaron a verse como el estrato más antiguo de la tradición textual budista, y por lo tanto como más genuinos. Así, por ejemplo, Oldenberg consideraba que de todos los budismos aún existentes en su tiempo, aquel que existía en Sri Lanka era el que conservaba un vínculo más directo con el budismo original: "Las tradiciones más antiguas del budismo son aquellas que se han preservado en Ceylán, y que han sido estudiadas por los monjes de aquella isla hasta el día de hoy" (76).

Se debe mencionar que Oldenberg no se encontraba solo en esta empresa. En 1881, el mismo año en que se publicó el Buddha en Alemania, el orientalista inglés T.W. Rhys-Davids fundó la Pali Text Society, una asociación dedicada al estudio y traducción de los textos pāli de la escuela Theravāda. Al igual que su contemporáneo y colega alemán, Rhys-Davids $^{5}$ tenía la firme convicción de que la tradición pāli representaba la esencia del budismo, y que en ella era posible hallar los estratos históricos más antiguos, los orígenes del budismo (Woodward, "The Biographical Imperative", 226).

Ahora bien, si alguien pretendía entender qué era el budismo y quién había sido realmente el Buddha, la única fuente de información fiable para estos estudiosos eran los textos pāli: "Es más que nada la tradición Pāli a la que debemos consultar cuando queremos conocer la información que se ha conservado sobre el Buddha y sobre su vida" (Oldenberg, 76). ${ }^{6}$

${ }^{5}$ Oldenberg y Rhys-Davids trabajaron juntos en la traducción de la versión pāli del Vinaya o código de reglas monásticas budistas. Se publicó en tres tomos entre el 1881 y el 1885 .

${ }^{6}$ La postura de Oldenberg minimizaba la labor de otros eruditos que se desempeñaban en el estudio de otras tradiciones budistas, como por ejemplo Alexander Csoma de Körös en el caso del budismo tibetano y Burnouf en el caso del budismo Mahāyāna, pues ¿qué validez tendría estudiar algo que no era el budismo genuino? 
Sin embargo, la elección de los textos pāli como la fuente original del budismo no carecía de complicaciones metodológicas. El hecho de considerarlos como más cercanos que otras tradiciones a la versión original del budismo, no quería decir que todo en ellos fuera genuino, $\mathrm{y}$ por ende que sirviera para los propósitos historicistas del Buddha. Se hacía necesario purgarlos de todo aquello que podía considerarse como adiciones, pues:

los siglos posteriores han dotado a la historia del Buddha con prodigios sobre prodigios en una escala completamente diferente de la de las épocas anteriores, y se dedicaron con una preferencia particular a rodear la figura del niño bendecido [el Buddha] con las creaciones más extravagantes de una imaginación sin límites (84).

Con todo, Oldenberg consideraba que era posible establecer una distinción clara entre los diferentes estratos temporales de la tradición $p \bar{a} l i$, de manera que se pudieran separar de forma precisa los elementos no históricos de la biografía del Buddha, y en una especie de decantación analítica conservar únicamente aquellos que sin duda alguna tuvieran un fundamento histórico:

Si ahora abstraemos de las tradiciones aquellas categorías que son completamente no históricas o al menos sospechosas de tener un carácter no histórico, entonces tendremos como núcleo sólido de los relatos del Buddha un conjunto de hechos reales que podremos reclamar como una adquisición ciertamente muy modesta, pero perfectamente segura para la historia (92).

Basado en estas premisas, Oldenberg construye una biografía del Buddha que pretende contener únicamente los episodios que son capaces de sostenerse en pie frente al escrutinio de la historia; es decir, hechos despojados de todo factor extraordinario que contenga un mínimo de elementos míticos. Pero entonces, según Oldenberg, ¿qué es lo que conforma la vida histórica del Buddha? Como él mismo debe reconocer, tenemos muy poco conocimiento acerca de eso: "Sabemos acerca de la región y de la familia de la que provenía. Sabemos acerca de sus padres, de la muerte temprana de su madre, y de la hermana de 
esta que crió al niño. Sabemos una serie de detalles de tipo similar que se extienden a lo largo de varias partes de su vida" (92).

En su depuración de elementos "no históricos", Oldenberg elimina de su biografía una serie de episodios altamente significativos para las tradiciones budistas: la concepción inmaculada, el nacimiento en Lumbin̄̄, el milagro de Śrāvastī y el descenso de los cielos en Sankasya, entre otros. ${ }^{7}$ Todos estos tienen un papel importante en la conformación de la imagen del Buddha como un personaje religioso de gran poder y soberanía, y están asociados con algunos de los sitios de peregrinación más importantes en la India budista.

Por otro lado, el autor despoja de todo elemento prodigioso a los episodios que conserva. Así por ejemplo, al discutir el despertar bajo el árbol Bodhi, omite la batalla con Māra, y la serie de eventos maravillosos que se produjeron a su alrededor. Reduce este momento decisivo para la historia del budismo a la experiencia interna de un individuo, sin tomar en cuenta las consecuencias universales que la tradición atribuye a este momento. Al analizar el episodio a través de la óptica de la ciencia histórica, Oldenberg se pregunta:

¿Existe algo de historia en este relato? Nos enfrentamos aquí con una de esas preguntas en la que es imposible que el cómputo del crítico histórico arroje un resultado puro y rotundo, un claro sí o un no. El carácter de las fuentes por sí mismo no garantiza que ante nosotros tengamos historia o mito. En las fuentes, la indudable verdad se mezcla con la indudable ficción; la historia de la obtención del Despertar no se reconoce ni como esto, ni como aquello (110).

Ya hemos discutido cómo para los budistas no existe esa separación entre mito e historia en lo que respecta al fundador de su religión. Por su parte, Oldenberg asume una visión completamente controversial al respecto. Para él, únicamente lo que se puede entender como histórico dentro del budismo es susceptible de considerarse como "original". Su postura puede parecer muy severa si la confrontamos con la posición propia

\footnotetext{
${ }^{7}$ Estos episodios, junto con el de la batalla con Māra, se encuentran entre los más representados en templos y monasterios, lo cual habla de su importancia para las tradiciones budistas.
} 
de las tradiciones budistas; sin embargo, es perfectamente comprensible si la analizamos a la luz de su lugar en la historia de los estudios budistas.

\section{El orientalismo alemán como Wissenschaft}

A diferencia de otros países europeos como Inglaterra, Francia, Holanda y Portugal, Alemania no tuvo intereses coloniales en el sur de Asia. ${ }^{8}$ Sin embargo, los estudios sobre esta región en particular se desarrollaron de una manera extraordinaria en ese país, de tal manera que "el tamaño de la inversión por parte del estado alemán en los estudios indológicos a lo largo del siglo xIx y la primera mitad del xx, [...] y el volumen de la producción del conocimiento orientalista alemán" rebasaron el del resto de Europa y Estados Unidos juntos (Pollock, “Deep Orientalism?”, 82).

Mientras que muchos orientalistas ingleses estudiaban temas de cultura y religión de la India como parte de un proyecto imperial diseñado para conocer y gobernar de manera más eficaz a sus colonizados indios, los alemanes, al carecer de un vínculo político con las regiones del sur de Asia, lo hacían motivados por otros intereses y necesidades propias de su contexto. Se pueden reconocer al menos dos tendencias principales en el orientalismo alemán: una que comienza con el movimiento romántico, y que se desarrolla en la primera mitad del siglo XIX, aunque también se prolonga más allá; y otra que se produce en la mitad del mismo siglo entre estudiosos preocupados por que las disciplinas humanísticas se convirtieran en verdaderas Wissenschaften, ciencias rigurosas y analíticas.

El orientalismo romántico alemán se puede ejemplificar con la famosa afirmación del poeta y filósofo Friedrich Schlegel: "todo, sí, todo sin excepción tiene su origen en la India" (apud King, "Orientalism and the Discovery of 'Buddhism'”, 147). Escritores y artistas románticos cultivaron la idea de un oriente místico que era la fuente de todo el conocimiento y de la solución a los problemas que angustiaban al hombre moderno. Encontraron en los textos hinduistas, principalmente

\footnotetext{
${ }^{8}$ Sus intereses coloniales se concentraron en varias regiones de África, en las Islas del Pacífico y en el Caribe americano.
} 
en la Bhagavadgìtā y en obras poéticas como Śakuntalā, un consuelo al mismo tiempo que una fuente inagotable de inspiración.

En parte, esta sobrevaloración de oriente, y especialmente de la India, obedecía a la búsqueda de una identidad ancestral germánica. El descubrimiento de la afinidad lingüística entre los pueblos indoeuropeos ayudó a construir la noción de que los pueblos germánicos tenían un lazo histórico estrecho con la India, y con las riquezas culturales que en ella se habían generado.

Sin embargo, para la mitad del siglo las cosas comenzaron a cambiar. Surgió la necesidad de traducir esta idealización ingenua de los románticos en hechos comprobables. Surgió una nueva generación de orientalistas alemanes, principalmente miembros de una clase media urbanizada y educada que valoraba las premisas del humanismo y la Ilustración: el uso de la razón, el rigor científico, el empiricismo y el cuestionamiento de la ortodoxia religiosa (Baumann, "Culture Contact and Valuation", 281). Gran parte de su ímpetu estaba dirigido a distanciarse explícitamente de sus antecesores:

se trataba claramente de una reacción a las ambiciones desmedidas de los románticos - y a los peligros que sus sistemas representaban para los ideales políticos, religiosos y científicos de la Ilustración. Esta generación no quería soñar, sino que quería hacerse incontrovertible y llegar a muy pocas conclusiones en vez de decir mucho (Marchand, German Orientalism, 75).

Este enfoque racionalista tuvo una influencia definitiva en el campo de los estudios budistas en Alemania. Se elaboró una imagen del budismo como una religión eminentemente racionalista en la cual los rituales y la fe tenían un papel mínimo frente a un sistema de conocimiento sofisticado dedicado a aprehender la "verdad"; "se elogió al budismo como la 'religión de la razón', la única religión que estaba fundamentada en el entendimiento y el conocimiento" (Baumann, "Culture Contact and Valuation", 275). ${ }^{9}$

${ }^{9}$ Esta empresa no era exclusiva de la academia alemana; en 1896, en su libro Buddhism: Its History and Literature, el inglés T. W. Rhys Davids argumentó que el budismo era una religión razonable e incluso científica (Clark, "Buddhist Passions", 75). 
Era este un momento en el que imperaba en algunos sectores académicos un cuestionamiento crítico de las religiones, y en especial del cristianismo, al que se veía como un sistema religioso incompatible con los avances del pensamiento racional y de las ciencias naturales. Para ellos el budismo era, más que una religión, una filosofía de vida, una ciencia del espíritu: “el budismo, como la 'religión de la razón', se representó como el 'contraste humanístico' de la religión cristiana, a la que valoraban como autoritaria y dogmática" (Baumann, "Culture Contact and Valuation", 43).

Esta sobrevaloración de los componentes racionales del budismo se desplazó también hacia la forma en que los eruditos alemanes concebían la figura del Buddha. Así como en sus estudios sobre la doctrina budista valoraron los aspectos filosóficos en detrimento de los devocionales, en lo que respecta a la persona del Buddha enfatizaron su papel como líder social y pensador progresista al mismo tiempo que ignoraron la dimensión mítica de su biografía, o bien la descartaron al considerarla como el producto de una fértil imaginación "tropical" (Marchand, German Orientalism, 271).

Esto es importante, pues al menos hasta la década de 1840, la vida del Buddha se asociaba más con mitos indoeuropeos y dioses indios, griegos y egipcios, que con una serie de sucesos y personajes históricos que se desarrollaron en la planicie gangética alrededor de los siglos VII y v antes de la E.C. Todavía en la década de 1850 había estudiosos que se preguntaban seriamente si en verdad había existido alguien conocido como el Buddha (Almond, "The Buddha-from Myth to History", 60).

Al confrontarlo con esta posición de incredulidad extrema, destaca el carácter innovador del Buddha. En él, Hermann Oldenberg propone una idea simple pero de grandes repercusiones: es posible reconocer huellas históricas en las tradiciones concernientes a la vida del Buddha, y reconstruir su biografía. Al estudioso le interesaba desmitificar las versiones tradicionales para extraer de ellas lo "genuino", lo "puro"; y en este proceso desmitificador creó una versión nueva, quizá un poco escueta si la comparamos con las tradicionales, pero perfectamente acorde con las necesidades de su época.

Este desplazamiento de la dimensión histórica del Buddha hacia un primer plano del debate académico puede verse, no únicamente como 
una postura parcial o prejuiciada sobre la dimensión mítica del budismo, sino también como una victoria para los ideales racionalistas del orientalismo alemán decimonónico que exigían consistencia histórica a los sistemas religiosos. En este sentido, Oldenberg creó un documento de la vida del Buddha que a la vez que cubría los requerimientos académicos de su época, brindaba fundamentos metodológicos para estudiar críticamente las tradiciones narrativas relacionadas con su vida y sus enseñanzas.

Paradójicamente, el proceso de desmitificación de la figura del Buddha, apoyado en gran parte por el Buddha de Oldenberg y por obras de otros de sus contemporáneos, permitió que un número reducido de racionalistas alemanes se involucraran de manera personal en la práctica budista como una alternativa religiosa (Baumann, "Culture Contact and Valuation", 279). El énfasis en la dimensión moral e intelectual del personaje de Buddha, atrajo a parte de una generación interesada en aprehender la verdad religiosa no a través de la revelación sino del razonamiento.

Lejos de mermar el interés académico y popular de los alemanes en el budismo, la obra de Oldenberg lo impulsó, pues al reconocer y analizar la existencia histórica del Buddha afirmó al mismo tiempo la validez de su doctrina "original", reconociéndola como el producto de la reflexión razonada de un personaje carismático y extraordinariamente sobresaliente en su época, y no como una mera elaboración del ingenio de pensadores religiosos anónimos.

\section{REFERENCIAS}

Almond, Philip, "The Buddha-from Myth to History", en The British Discovery of Buddhism, Cambridge, Cambridge University Press, 1988, 54-79.

Baumann, Martin, "Culture Contact and Valuation: Early German Buddhists and the Creation of a 'Buddhism in Protestant Shape'", Numen, 44, 3, 1997, 270-295.

CHо, Sungtaek, "The Rationalist Tendency in Modern Buddhist Scholarship: A Revaluation", Philosophy East and West, 52, 4, 2002, 426-440.

Clark, J., "Buddhist Passions. The Nineteenth Century", en Oriental Enlightenment: The Encounter between Asian and Western Thought, London, Routledge, 2003, 71-94. 
King, Richard, "Orientalism and the Discovery of 'Buddhism", en Orientalism and Religion Postcolonial Theory, India and 'The Mystic East', London, Routledge, 2001, 143-160.

Marchand, Suzanne, German Orientalism in the Age of Empire. Religion, Race, and Scholarship, Cambridge, Cambridge University Press, 2009.

Oldenderg, Hermann, Buddha. Sein Leben, seine Lehre, seine Gemeinde, Berlin, Verlag von Wilhelm Hertz, 1881.

Pollock, Sheldon, "Deep Orientalism? Notes on Sanskrit and Power Beyond the Raj", en Orientalism and the Postcolonial Predicament: Perspectives On South Asia, Carol A. Breckenridge y Peter van der Veer (eds.), Philadelphia, University of Pennsylvania Press, 1994, 76-133.

RAY, Reginald, "Buddha Śākyamuni as a Saint", en Buddhist Saints in India. A Study in Buddhist Values and Orientations, Oxford, Oxford University Press, 1994, 44-78.

Shaner, David, "Biographies of the Buddha", Philosophy East and West, 37, 3, 1987, 306-322.

SchoBer, Juliane, "Trajectories in Buddhist Sacred Biography", en Sacred Biography in the Buddhist Traditions of South and Southeast Asia, Juliane Schober (ed.), Delhi, Motilal Banarsidass, 2002, 1-18.

Welbon, Guy, "Hermann Oldenberg and the Silent Buddha", en The Buddhist Nirvāna and Its Western Interpreters, Chicago, University of Chicago Press, 1968, 194-220.

Woodward, Mark, "The Biographical Imperative in Theravāda Buddhism”, en Sacred Biography in the Buddhist Traditions of South and Southeast Asia, Juliane Schober (ed.), Delhi, Motilal Banarsidass, 2002, 40-63. 
